Vol. 5, No. 2, 2019

Volodymyr Zelenyak ${ }^{1}$, Liubov Kolyasa ${ }^{2}$

1. Department of Mathematics, Lviv Polytechnic National University, Ukraine, Lviv, S. Bandery Street, 12, ORCID 0000-0002-6653-4326, E-mail: volodymyr.zelenyak@gmail.com

2. Department of Mathematics, Lviv Polytechnic National University, Ukraine, Lviv, S. Bandery Street, 12, ORCID 0000-0002-9690-8042, E-mail: kolyasa.lubov@ gmail.com

\title{
MODELING OF ELASTIC STATE FOR TWO JOINED DISSIMILAR SEMI-INFINITE PLATES WITH CRACK UNDER THE ACTION OF PRESSURE ON THE SHORES OF THE CRACK
}

Received: April 21, 2019 / Revised: June 15, 2019 / Accepted: August 30, 2019

(C) Zelenyak V., Kolyasa L., 2019

Abstract. Purpose. A two-dimensional mathematical model for the problem of elasticity theory on joined dissimilar elastic half-planes containing rectilinear crack under the action of mechanical efforts on the shores of a crack is examined. As a consequence, the intensity of stresses in the vicinity of tops of the crack increases, which significantly affects strength of the body. This may lead to the growth of a crack and to the local destruction of a structure. Such a model represents to some extent a mechanism of destruction of the elements of engineering structures with cracks, we determined stress intensity factors (SIF) at the tops of the crack, which are subsequently used to determine critical values of the normal pressure on the shores of the crack. Therefore the aim of present work is to determine the two-dimensional elastic state in joined dissimilar half-endless plates containing a rectilinear randomly-oriented crack under conditions of power load on the shores of the crack. This will make it possible to determine critical values of mechanical load on the shores of a crack in order to prevent crack growth, which will not allow the local destruction of the body.

Methodology. The methods of studying two-dimensional elastic state body with crack as stress concentrators based on the function of complex variable method by which the problem of stationary elasticity are reduced to a SIF of the first kind, a numerical solution which was obtained by the method of mechanical quadratures.

Findings. In this paper, two-dimensional mathematical model in the form of singular integral equations on the contours of cracks in order to determine perturbed power stresses due to the presence of cracks are obtained; numerical solutions to singular integral equations of the problem of elasticity theory for a specified region under the action of normally distributed pressure on the shores of the crack are found; stress intensity factors at the tops of a crack and to detect the effects of mechanical character are identify and explored. Graphical dependences of SIF, which characterize distribution of the intensity of stresses at the tops of a crack, on the angle of crack inclination and elastic characteristics of half-planes is obtained. This makes it possible to analyze the intensity of stresses in the vicinity of a crack's tops depending on the geometrical and mechanical factors, as well as to determine the limit of permissible values of normal pressure on the shores of the crack at which the growth of the crack starts, as well as the local destruction of the body. It is shown that the proper selection of elastic characteristics of the components of joined dissimilar half-planes can help achieve an improvement in the strength of the body in terms of the mechanics of destruction by reducing SIF at the crack's tops.

Originality. Scientific novelty lies in the fact that the solutions of the new two-dimensional problems of elasticity for a specified region ( joined dissimilar half-endless plates containing a rectilinear randomly-oriented crack ) under the action of normally distributed pressure on the shores of the crack are obtained.

Practical value. Practical value of the present work lies in the possibility of a more complete 
accounting of actual stressed-strained state in the piecewise-homogeneous elements of a structure with cracks that work under conditions of different mechanical loads. The results of specific studies that are given in the form of graphs could be used when designing rational operational modes of structural elements. In this case, the possibility is obtained for preventing the growth of a crack through the appropriate selection of composite's components with the corresponding mechanical characteristics.

Keywords: stress intensity factors, singular integral equation, normally distributed pressure, joined dissimilar plate.

\section{Introduction. Topicality of the research and literature review}

In real solid bodies that are the elements of engineering structures, there is always a certain amount of micro defects whose growth under the influence of the applied power loads leads to the emergence of cracks resulting in local or total destruction of the body. Practice shows that such a phenomenon is characteristic of high-strength and low-plastic materials. Therefore, it is important theoretically and practically to study stress distribution in the vicinity of stress concentrators of the crack type. In this case, the intensity of stresses at the top of the cracks is expressed by stress intensity factors (SIF). These parameters make it possible to determine threshold value of power load at which a crack starts to grow with the body being locally destroyed.

Research on elastic state in the joined dissimilar half-planes with cracks is addressed in a number of publications. In particular, a crack was studied, located in parallel to the lines of junction of dissimilar halfplanes when stretching stresses are assigned on the infinity of the formed plane [1]. Thermoelastic problem for such a region with uniform distribution of temperature over entire piecewise-homogeneous plane with a crack was examined in [2], [3].

In paper [4], authors in a two-dimensional model considered a problem on bending a plate weakened by coaxial crack and slit. The resulting solution makes it possible to analyze the effect of the interaction of variable-type defects on the stressed state near tops.

Authors of [5] analyzed elastic interaction between two spherical cracks, located along the outer surface of hollow parts, placed in a heterogeneous environment during action of an uniaxial stretching load.

Authors of [6] obtained analytical solution to a two-dimensional problem of elasticity theory of screw dislocation near the surface crack of mode III, a shear crack during action of anti-flat deformation. They determined effect of the dislocation on a stress intensity coefficient.

In paper [7], a problem of interaction between a crack and an elastic inclusion was reduced to solving singular integral equations of the Cauchy type. Based on this result, the authors analyzed singular behavior of the solution for a crack with branches.

Based on the numerical solution to the bound three-dimensional elastic-dynamic problem, the influence of massive inclusion of the hard disk on the adjacent slit-like crack was examined in [8].

A problem on the circular, absolutely rigid, inclusion of arbitrary shape, which is located in the transversally isotropic half-space under conditions of smooth contact with the second half-space, was reduced to a system of two-dimensional singular integral equations. Authors of [9] investigated the asymptotes of stresses in the vicinity of an inclusion and defined directions of the largest and the lowest concentration of stresses.

In article [10], a problem of elasticity theory for a half-plane with many cracks was reduced to a singular integral equation using the modified comprehensive potential under condition of free stretching. The authors obtained a system of singular integral equations with a distributed dislocation function.

The method of singular integral equations was used too for the analysis of the plane elastic state in a half space locally heated over a part of its free surface by a heat flow and containing an internal arbitrary oriented rectilinear crack [11] or edge crack [12].

An analysis of major scientific literary sources revealed that still unexplored and undeveloped are the mathematical models, which are applied to study the interaction between a crack and the line that 
connects two dissimilar half-planes, as well as the intersection of a crack with the line of junction of halfplanes in piecewise homogeneous bodies with cracks. Given this, there is a necessity to construct mathematical models for determining such mechanical loads at which a crack starts to grow while the body undergoes local destruction. Exploring such models will make it possible to propose one of the approaches, for example by selecting the components of half-planes, welded together, with appropriate mechanical characteristics, to prevent the growth of a crack.

\section{Mathematical model}

We shall consider two joined dissimilar half-planes $s^{+}$and $S^{-}$with a junction line $L_{0}$, along which there is a perfect mechanical contact (equality of stresses and displacements). The lower half-plane is weakened by rectilinear crack $L_{1}$ of length $2 l_{1}$ with a center point $(0 ;-i h)$. The crack forms angle $\alpha$ with the $O x$ axis with an evenly distributed normal pressure of intensity $p$ assigned on the shores (Fig. 1, a).

Assume that a perfect mechanical contact is assigned on contour $L_{0}$ :

$$
\begin{aligned}
& {\left[N\left(t_{0}\right)+i T\left(t_{0}\right)\right]^{+}=\left[N\left(t_{0}\right)+i T\left(t_{0}\right)\right]^{-} ;} \\
& \left(u_{0}+i v_{0}\right)^{+}-\left(u_{0}+i v_{0}\right)^{-}=0, \quad t_{0} \in L_{0},
\end{aligned}
$$

the shores of the cracks do not contact in the process of deformation and a self-equilibrium load is set on them:

$$
\left[N\left(t_{1}\right)+i T\left(t_{1}\right)\right]^{ \pm}=p_{1}^{*}\left(t_{1}\right)
$$

where $t_{1}$ is the complex coordinate of the point on contour $L_{1}$ in the $x O y$ coordinate system.

Complex potentials $\Phi(z), \Psi(z)$ will be selected in the following form [1]:

$$
\Phi(z)=\Phi_{1}(z)+\Phi_{2}(z), \quad \Psi(z)=\Psi_{1}(z)+\Psi_{2}(z),
$$

where

$$
\begin{aligned}
& \Phi_{1}(z)=\frac{1}{2 \pi} \int_{L_{1}} \frac{g^{\prime}{ }_{1}\left(t_{1}\right) e^{i \alpha} d t_{1}}{\zeta_{1}-z} ; \\
& \zeta_{1}=t_{1} e^{i \alpha}+z_{1}^{0} \\
& \Psi_{1}(z)=\frac{1}{2 \pi} \int_{L_{1}}\left[\frac{\overline{g_{1}^{\prime}\left(t_{1}\right)} e^{-i \alpha} \overline{d t_{1}}}{\zeta_{1}-z}-\frac{\bar{\zeta}_{1} g_{1}^{\prime}\left(t_{1}\right) e^{i \alpha} d t_{1}}{\left(\zeta_{1}-z\right)^{2}}\right] \text {; } \\
& \Phi_{2}(z)=\frac{1-\Gamma_{0}}{2 \pi\left(1+\chi_{-} \Gamma_{0}\right)} \int_{L_{1}}\left[\frac{g_{1}^{\prime}\left(t_{1}\right) e^{i \alpha} d t_{1}}{z-\overline{\zeta_{1}}}+\frac{\left(\zeta_{1}-\overline{\zeta_{1}}\right) \overline{g_{1}^{\prime}\left(t_{1}\right)} e^{-i \alpha} \overline{d t_{1}}}{\left(\overline{\zeta_{1}}-z\right)^{2}}\right] \text {; } \\
& \Psi_{2}(z)=\frac{1-\Gamma_{0}}{2 \pi\left(1+\chi_{-} \Gamma_{0}\right)} \int_{L_{1}}\left\{\frac{\overline{\zeta_{k}} g_{1}^{\prime}\left(t_{1}\right) e^{i \alpha} d t_{1}}{\left(\overline{\zeta_{1}}-z\right)^{2}}+\left[\frac{\left(\overline{\zeta_{1}}-\zeta_{1}\right)\left(\overline{\zeta_{1}}+z\right)}{\left(\overline{\zeta_{1}}-z\right)^{3}}-\frac{1}{\overline{\zeta_{1}}-z}\right] \overline{g^{\prime}\left(t_{1}\right)} e^{-i \alpha} \overline{d t_{1}}\right\} .
\end{aligned}
$$

We shall note that the choice of complex potentials in the form (3) provides exact satisfaction of the second equality of boundary condition (1) on contour $L_{0}$. As a consequence, the order of the system of integral equations, which we obtain after fulfillment of the remaining boundary conditions is reduced by unity.

By satisfying employing integral representations (3), and the boundary conditions on crack contour (2), we shall obtain a singular equations of the first kind relative to the one unknown function on crack contour $L_{1}$ in which the right side equals to $p_{1}^{*}\left(\tau_{1}\right)=-p$ :

$$
\frac{1}{2 \pi} \int_{L_{1}}\left[R_{11}\left(t_{1}, \tau_{1}\right) g_{1}^{\prime}\left(t_{1}\right) \mathrm{d} t_{1}+S_{11}\left(t_{1}, \tau_{1}\right) \overline{g_{1}^{\prime}\left(t_{1}\right)} \overline{d t_{1}}\right]=p_{1}^{*}\left(\tau_{1}\right), \quad \tau_{1} \in L_{1},
$$

and that has the only solution provided the condition is satisfied:

$$
\int_{L_{1}} g_{1}^{\prime}\left(t_{1}\right) \mathrm{d} t_{1}=0
$$


which ensures the uniqueness of displacements when bypassing the contour of the crack.

In formulas (4) and (5), we used:

$$
\begin{gathered}
R_{11}\left(t_{1}, \tau_{1}\right)=R_{11}^{1}\left(t_{1}, \tau_{1}\right)-\frac{1-\Gamma_{0}}{1+\chi_{-} \Gamma_{0}} e^{i \alpha_{1}}\left\{\frac{1}{\overline{T_{11}}}-\frac{\left(\overline{\zeta_{1}}-\zeta_{1}\right)}{T_{11}^{2}}-e^{-2 i \alpha_{1}} \cdot \frac{\left(2 \eta_{1}-\zeta_{1}-\overline{\eta_{1}}\right)\left(\overline{\zeta_{1}}-\zeta_{1}\right)}{T_{11}^{3}}-\frac{1}{T_{11}}\right\} ; \\
S_{11}\left(t_{1}, \tau_{1}\right)=S_{11}^{1}\left(t_{1}, \tau_{1}\right)+\frac{1-\Gamma_{0}}{1+\chi_{-} \Gamma_{0}} e^{-i \alpha_{1}}\left[\frac{\left(\zeta_{1}-\overline{\zeta_{1}}\right)}{\overline{T_{11}^{2}}}-\frac{1}{T_{11}}+e^{-2 i \alpha_{1}} \cdot \frac{H_{11}}{T_{11}^{2}}\right] ; \\
R_{11}^{1}\left(t_{1}, \tau_{1}\right)=e^{i \alpha_{1}}\left[\frac{1}{H_{11}}+\frac{e^{-2 i a_{1}}}{\overline{H_{11}}}\right] ; \quad S_{11}^{1}\left(t_{1}, \tau_{1}\right)=e^{-i \alpha_{1}}\left[\frac{1}{\bar{H}_{11}}-\frac{e^{-2 i \alpha_{1}} H_{11}}{\overline{H_{11}^{2}}}\right] ; \\
H_{11}=\zeta_{1}-\eta_{1} ; \quad T_{11}=\zeta_{1}-\overline{\eta_{1}} ; \quad \zeta_{1}=t_{1} e^{i \alpha}+z_{1}^{0} ; \quad \eta_{1}=\tau_{1} e^{i \alpha}+z_{1}^{0},
\end{gathered}
$$

where $\Gamma_{0}=G_{+} / G_{-} ; G_{+}\left(G_{-}\right)$is the shear modulus; $\mu^{+}\left(\mu^{-}\right)$is the Poisson's ratio of the upper (lower) half-plane, respectively; $\chi=(3-\mu) /(1+\mu)$ is for the generalized flat stressed state; $g^{\prime}{ }_{1}\left(t_{1}\right)$ are the unknown derivatives from a jump of displacements for crossing a line of cracks. Functions $g^{\prime}{ }_{1}\left(t_{1}\right)$ should possess integrated features at the ends of the crack.

\section{Numerical algorithm}

By substituting $t_{1}=l_{1} \xi, \tau_{1}=l_{1} \eta$, we record the integral equation (1) in the parameterized form:

$$
\int_{-1}^{1}\left[R_{11}^{*}(\xi, \eta) \psi_{1}(\xi)+S_{11}^{*}(\xi, \eta) \overline{\psi_{1}(\xi)}\right] d \xi=2 \pi R_{1}(\eta), \quad|\eta|<1
$$

where

$$
\begin{aligned}
\psi_{1}(\xi)=g_{1}{ }_{1}\left(l_{1} \xi\right) ; & R_{1}(\eta)=p_{1}^{*}\left(\eta_{1}\right) ; \\
R_{11}^{*}(\xi, \eta)=l_{1} R_{11}\left(l_{1} \xi, l_{1} \eta\right) ; & S_{11}^{*}(\xi, \eta)=l_{1} S_{11}\left(l_{1} \xi, l_{1} \eta\right) .
\end{aligned}
$$

Condition (2) will take the form:

$$
\int_{-1}^{1} \psi_{1}(\xi) d \xi+=0
$$

Function $\psi_{1}(\eta)$ can be represented in the form $\psi_{1}(\eta)=u_{1}(\eta) / \sqrt{1-\eta^{2}}$.

By applying to integral equations (3) and condition (4) the quadrature formulae of GaussianChebyshev, we shall obtain a system of $n$ algebraic equations for determining $n$ unknown functions $u_{1}\left(\xi_{k}\right), k=1,2 \ldots n$ :

$$
\begin{gathered}
\frac{1}{n} \sum_{k=1}^{n}\left[R_{11}^{*}\left(\xi_{k}, \eta_{m}\right) u_{1}\left(\xi_{k}\right)+S_{11}^{*}\left(\xi_{k}, \eta_{m}\right) u_{1}\left(\xi_{k}\right)\right]=2 \pi R_{1}\left(\eta_{m}\right), \quad m=1,2, \ldots ., n-1 ; \\
\sum_{k=1}^{n} u_{1}\left(\xi_{k}\right)=0,
\end{gathered}
$$

where $\xi_{k}=\cos (\pi(2 k-1) / 2 k) ; \eta_{m}=\cos (\pi m / n)$.

We have expressions [13] for stress intensity factors (SIF) $K_{I}^{ \pm}, K_{I I}^{ \pm}$in the lower (-) and upper (+) tops of crack:

where

$$
K_{I}^{ \pm}-i K_{I I}^{ \pm}=\mp u_{1}( \pm 1) \sqrt{l},
$$

$$
\begin{aligned}
& u_{1}(1)=-\frac{1}{n} \sum_{k=1}^{n}(-1)^{k} u_{1}\left(\xi_{k}\right) \operatorname{ctg} \frac{2 k-1}{4 n} \pi ; \\
& u_{1}(-1)=\frac{1}{n} \sum_{k=1}^{n}(-1)^{k+n} u_{1}\left(\xi_{k}\right) \operatorname{tg} \frac{2 k-1}{4 n} \pi .
\end{aligned}
$$




\section{Modeling of Elastic State for Two Joined Dissimilar Semi-Infinite Plates with Crack ...}

In these formulas, SIF $K_{I}^{ \pm}, K_{I I}^{ \pm}$are real quantities that characterize the stress-strain state in the vicinity of the crack tips.

\section{Analysis of the obtained numerical results}

Given that evenly distributed normal pressure $p$ is assigned on the shores of the crack, the right sides in equations (1) will take the form $p_{1}^{*}\left(\tau_{1}\right)=-p$.

Graphs for the dimensionless stress intensity factors $K_{I} / K_{0}$ and $K_{I I} / K_{0}\left(K_{0}=p \sqrt{l}\right)$, in the case of an arbitrarily oriented crack, are shown in Figs. 1 and 2.

We constructed dependences of stress intensity factors on the crack inclination angle $\alpha$ for different values of parameter $\lambda=1 / h$ when $G_{+} / G_{-}=0.5$ (Fig. 1, a; Fig. 2, a), and $G_{+} / G_{-}=2$ (Fig. 1, b, Fig. 2, b). Solid curves correspond to the coefficients of intensity at the right top of the crack closest to the line of separation of half-planes, and dashed curves - at the left. The numerical solution of integral equations (5), (6) was obtained by the method of mechanical quadratures [13] at $\chi_{+}=\chi_{-}=2$.

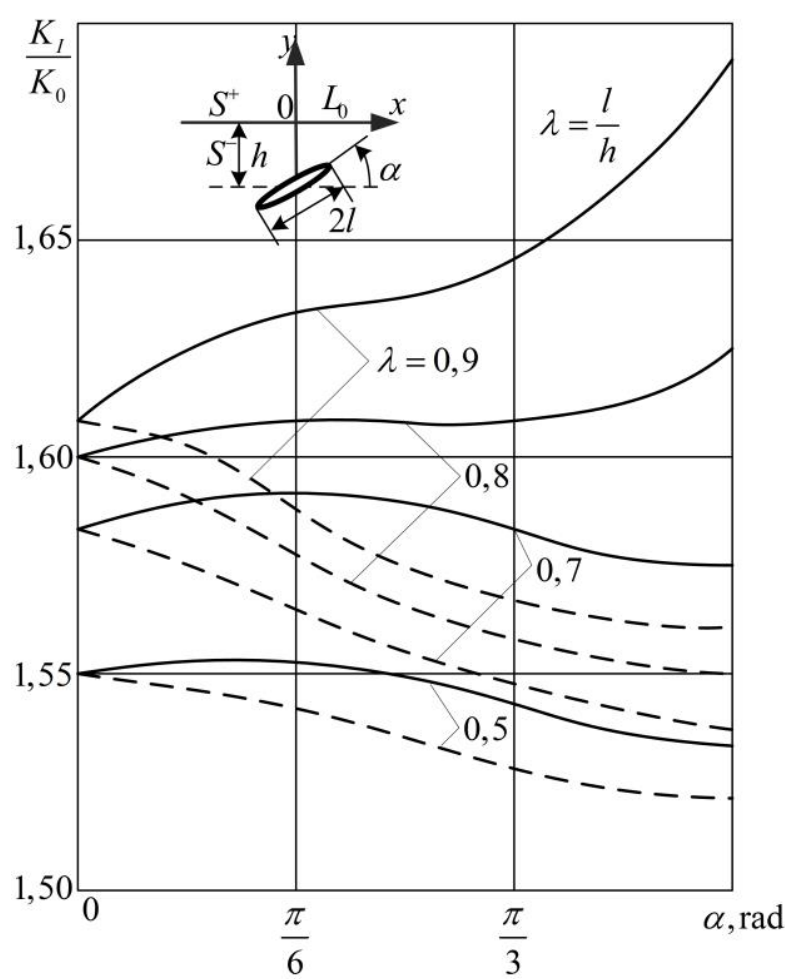

a

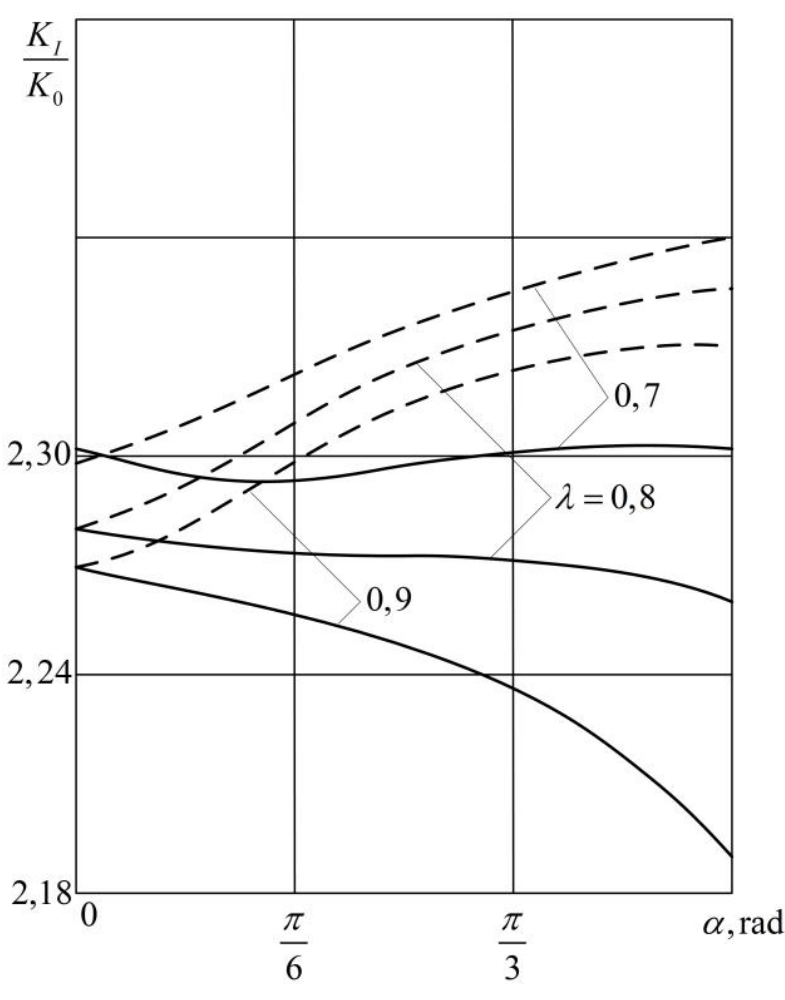

$\mathrm{b}$

Fig. 1. Dependence of dimensionless SIF $K_{I} / K_{0}$ on the angle of inclination of the crack $\alpha$ :

$$
\mathrm{a}-G_{+} / G_{-}=0.5 ; \mathrm{b}-G_{+} / G_{-}=2
$$

Stress intensity factor $K_{I} / K_{0}$ is always greater (smaller) for that top of the crack that is closer to the upper softer (more rigid) half-plane (Fig. 1, a, b). At a significant distance from the crack from the upper less stiff $\left(G_{+}<G_{-}\right)$half-plane, the factor $K_{I} / K_{0}$ accepts maximum values at $\alpha=0$ (a crack is parallel to the line of separation of $L_{0}$ ). With the crack approaching the boundary of division, the maximum of factor $K_{I} / K_{0}$ shifts to angle $\alpha=\pi / 2$ (Fig. 1, a). If the upper half-plane is more rigid $\left(G_{+}>G_{-}\right)$, then the maximum of factor $K_{I} / K_{0}$ is always achieved at $\alpha=\pi / 2$ for a more remote top of the crack (Fig. 1, b). Stress intensity factor $K_{I I} / K_{0}$ is always greater for the top of the crack, which is closer to the line of separation of half-planes, regardless of the rigidity of the upper half-plane. In this case, stress intensity coefficient $K_{I I} / K_{0}$ accepts a maximum value for the angles of inclination of a crack close to $\alpha=\pi / 6$ (Fig. 2, a, b). 


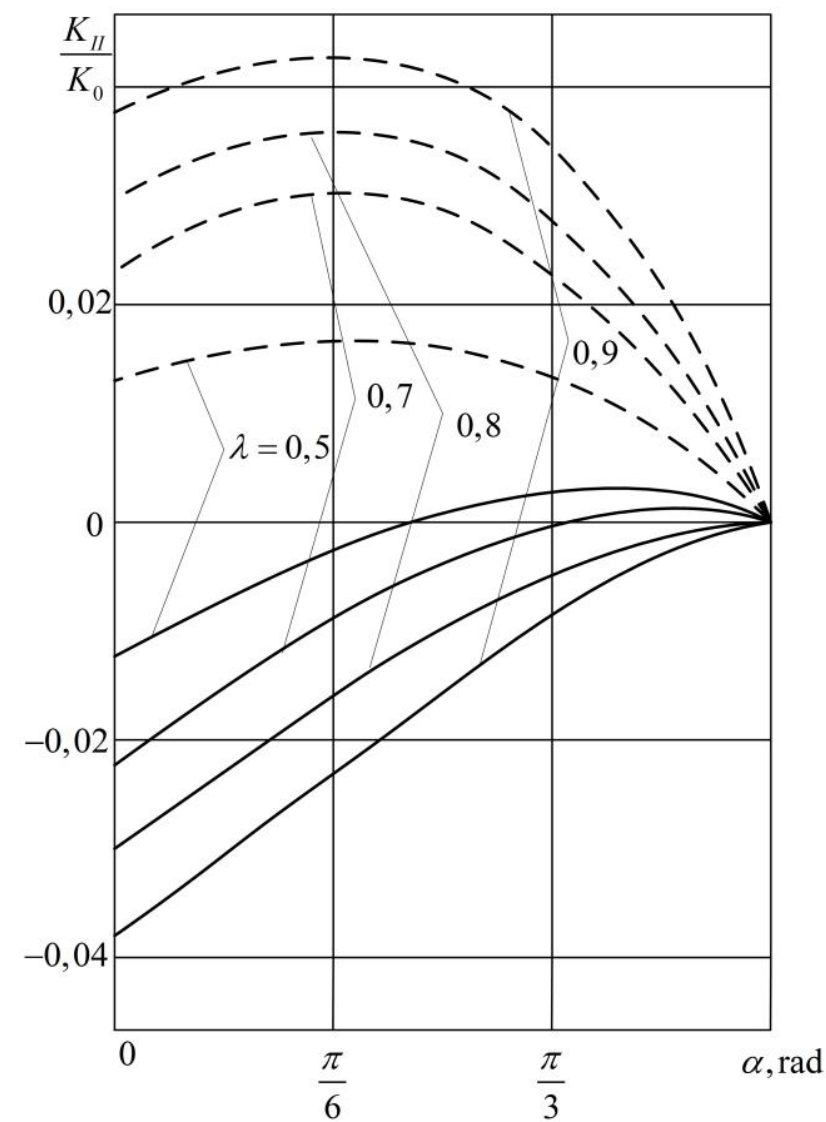

a

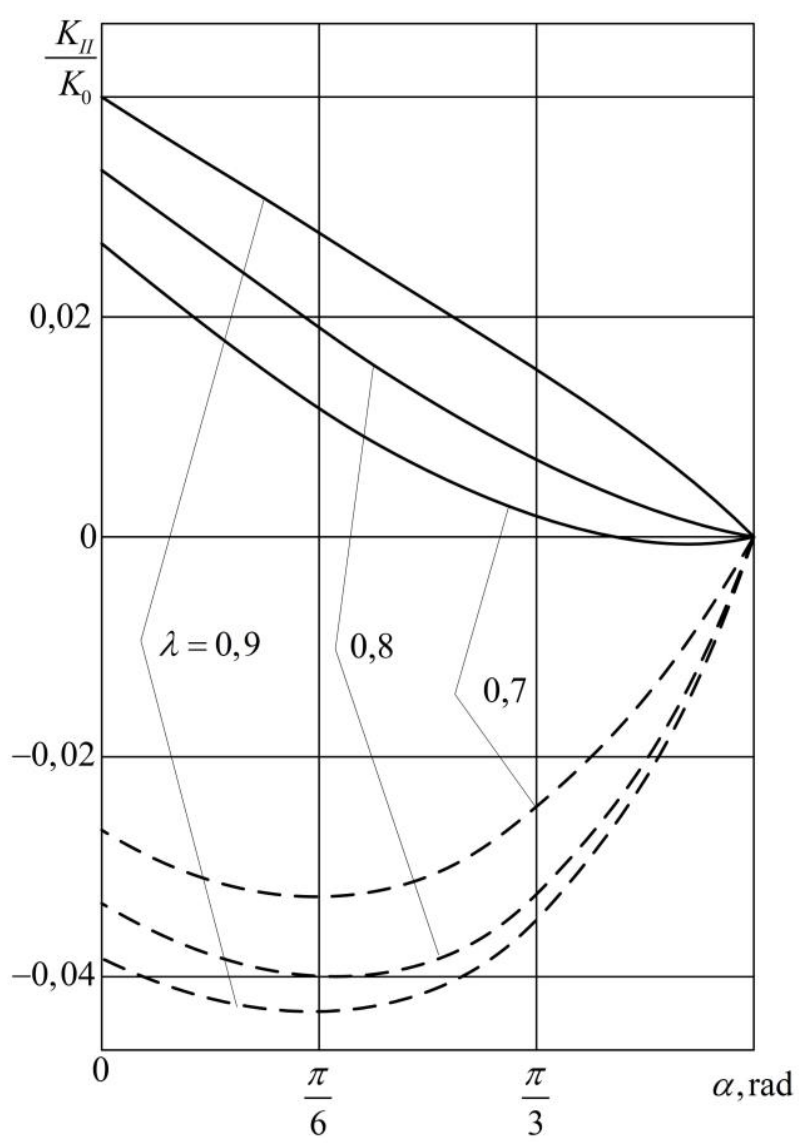

b

Fig. 2. Dependence of dimensionless SIF $K_{I I} / K_{0}$ on the angle of inclination of the crack $\alpha$ :

$$
\mathrm{a}-G_{+} / G_{-}=0.5 ; \mathrm{b}-G_{+} / G_{-}=2
$$

In the problem on two joined half-planes with an arbitrarily oriented straight crack the shores of the crack do not touch. Then, according to $\sigma_{\theta}$-criterion (crack original growth hypothesis), it is possible to derive critical values for normal pressure of intensity $p_{c v}$, when the body starts breaking down locally, using the equations of boundary equilibrium [14] $\cos ^{3} \frac{\theta_{*}^{ \pm}}{2}\left(K_{\mathrm{I}}^{ \pm}-3 K_{\mathrm{II}}^{ \pm} \operatorname{tg} \frac{\theta_{*}^{ \pm}}{2}\right)=\frac{K_{1 C}}{\sqrt{\pi}}$ as follows:

$$
p_{c v}=\frac{1}{\sqrt{\pi l}} \cdot \frac{K_{1 C}}{\cos ^{3} \frac{\theta_{*}^{ \pm}}{2}\left(k_{1}^{ \pm}-3 k_{2}^{ \pm} \operatorname{tg} \frac{\theta_{*}^{ \pm}}{2}\right)},
$$

where $k_{1}^{ \pm}=K_{I}^{ \pm} / K_{0} ; \quad k_{2}^{ \pm}=K_{I I}^{ \pm} / K_{0} ; \quad K_{0}=p \sqrt{l} ; \quad K_{1 C}$ is the constant that characterizes resistance of a material to destruction and which is determined experimentally; $\theta_{*}^{ \pm}=2 \operatorname{arctg} \frac{k_{1}^{ \pm}-\sqrt{\left(k_{1}^{ \pm}\right)^{2}+8\left(k_{2}^{ \pm}\right)^{2}}}{4 k_{2}^{ \pm}}$; $\theta_{*}^{ \pm}$are the angles of original crack growth from tops $l^{ \pm}$.

It follows from the numerical results presented in Table 1 that with a crack's top approaching junction line with a more rigid environment $\left(G_{+}>G_{-}\right)$, the critical value of the intensity of normal pressure $p_{c v}$ grows, while with a less rigid environment $\left(G_{+}<G_{-}\right)$-reduces.

The present study is continuation of previously examined problems on the piecewise-homogeneous bodies of similar geometry under the action of heat load and is extension to be applied for mechanical stresses. 
Modeling of Elastic State for Two Joined Dissimilar Semi-Infinite Plates with Crack ...

Table 1

Relative values of normal pressure intensity on the shores of crack $\tilde{p} / p_{c v}$ for different angles of inclination of the crack $\alpha$ (parameter $\lambda=1 / h=0.9$ )

\begin{tabular}{|c|c|c|c|c|}
\hline \multirow{2}{*}{$\alpha$} & \multicolumn{2}{|c|}{$G_{+} / G_{-}=0.5$} & \multicolumn{2}{c|}{$G_{+} / G_{-}=2$} \\
\cline { 2 - 5 } & $l^{-}$ & $l^{+}$ & $l^{-}$ & $l^{+}$ \\
\hline 0 & 0.632 & 0.632 & 0.438 & 0.438 \\
\hline$\pi / 6$ & 0.634 & 0.624 & 0.436 & 0.443 \\
\hline$\pi / 3$ & 0.638 & 0.612 & 0.432 & 0.449 \\
\hline$\pi / 2$ & 0.640 & 0.595 & 0.430 & 0.456 \\
\hline
\end{tabular}

\section{Conclusions}

1. A two-dimensional mathematical model for the problem of elasticity theory for two joined dissimilar half-planes with crack in the form of singular integral equation (SIE) of the first kind on the contours of crack is constructed. Such an approach makes it possible to obtain a numerical solution to SIE by the application of the high precision method of mechanical quadratures.

2. Numerical solutions to SIE (employing the method of mechanical quadratures) in particular case of two joined dissimilar half-planes with one randomly-oriented crack, when uniformly distributed normal pressure acts on the shores of the crack, is obtained. This makes it possible to determine stress intensity factors (SIF) at the tops of the crack, which are subsequently used to determine critical values of the normal pressure on the shores of the crack at which a crack starts to grow.

3. Graphical dependences of SIF $K_{I}^{ \pm}, K_{I I}^{ \pm}$, which characterize the distribution of intensity of stresses at the tops of a crack, on the angle of crack inclination and elastic characteristics of half-planes is constructed. We determined relative critical values of normal pressure on the shores of the crack from the equations of equilibrium for different angles of crack inclination. These results make it possible to determine the limit of permissible values of normal pressure on the shores of the crack and could be used when designing rational operational modes of structures' elements in terms of preventing the growth of cracks.

\section{References}

[1] V. Zeleniak, R. Martyniak, B. Slobodian, "Napruzhennia v spaianykh riznoridnykh pivploshchynakh z vkliuchenniam i trishchynoiu za dii roztiahu" ["Stress in soldered heterogeneous half-planes with inclusion and crack under the action of tension"], Visnyk Natsionalnoho universytetu "Lvivska politekhnika» [Bulletin of Lviv Polytechnic National University], vol. 625, pp. 54-58, 2008. [in Ukrainian].

[2] M. P. Savruk, V. M. Zelenyak, "Plane problem of thermal conductivity and thermal elasticity for two joined dissimilar half-planes with curved inclusions and cracks", Soviet Materials Science, vol. 24, no. 2, pp. 124-129, 1988.

[3] V. Zeleniak, and B. Slobodian, Modeliuvannia termopruzhnoho dvovymirnoho stanu dvokh spaianykh riznoridnykh pivploshchyn z vkliuchenniamy i trishchynamy ["Modelling of thermoelastic two-dimensional state of bonded heterogeneous halfplanes with inclusions and cracks"], Fizyko-matematychne modeliuvannia ta informatsiyni tekhnolohiy [Physico-mathematical modeling and informational technologies], vol. 12, pp. 94-101, 2010. [in Ukrainian].

[4] I. P. Shatskyi, T. M. Daliak, "Vzaiemodiya trishchyny z kolinearnoiu shchilynoiu za zghynu plastyny" ["Interaction of crack and collinear slot in plate bending"], Visnyk Zaporizkoho natsionalnoho universytetu [Bulletin of Zaporizhzhia National University], no. 1, pp. 211-218, 2015. [in Ukrainian].

[5] N. Gupta, G. Tagliavia, M. Porfiri, "Elastic interaction of interfacial spherical-cap cracks in hollow particle filled composites", International Journal of Solids and Structures, vol. 48, no. 7-8, pp. 1141-1153, 2011.

[6] S. N. G. Chu, "Elastic interaction between a screw dislocation and surface crack", Journal of Applied Physics, vol. 53, no. 12, pp. 8678-8685, 1982.

[7] Z. Ming-huan, T. Ren-ji, "Interaction between crack and elastic inclusion", Applied Mathematics and Mechanics, vol. 16, no. 4, pp. 307-318, 1995. 
[8] V. V. Mykhas'kiv, O. M. Khay, "Interaction between rigid-disc inclusion and penny-shaped crack under elastic time-harmonic wave incidence”, International Journal of Solids and Structures, vol. 46, no. 3-4,pp. 602-616, 2009.

[9] O. F. Kryvyy, "Interface circular inclusion under mixed conditions of interaction with a piecewise homogeneous transversally isotropic space”, Journal of Mathematical Sciences, vol. 184, no. 1, pp. 101-109, 2012.

[10] N. R. F. Elfakhakhre, N. M. A. Nik long, Z. K. Eshkuvatov, "Stress intensity factor for multiple cracks in half plane elasticity" in Proc. of 2nd International Conference and Workshop on Mathematical Analysis 2016 (ICWOMA2016), Langkawi, Malaysia, August 2-4, 2016, pp. 020010-1-020010-8.

[11] S. Konechnyj, A. Evtushenko, V. Zelenyak, "The effect of the shape of distribution of the friction heat flow on the stress-strain state of a semispace", Trenie i Iznos [Friction and Wear], vol. 23, no. 2, pp. 115-119, 2002.

[12] S. Konechny, A. Evtushenko, V. Zelenyak, "Heating of the semispace with edge cracks by friction", Trenie i Iznos [Friction and Wear], vol. 22, no. 1, pp. 39-45, 2001.

[13] M. P. Savruk, Dvumernye zadachi uprugosti dlya tel s treshchinami [Two-dimensional elasticity problems for bodies with cracks]. Kyiv, Ukraine: Naukova dumka Publ., 1981. [in Russian].

[14] V. V. Panasyuk, M. P. Savruk, A. P. Datsyshin, Raspredelenie napryazheniy okolo treshchin v plastinah $i$ obolochkah [Distribution of stresses near cracks in plates and shells]. Kyiv, Ukraine: Naukova dumka Publ., 1976. [in Russian]. 